\title{
Estudo do comportamento tribológico do par liga Babbitt - aço ABNT 1045 quando variadas a espessura e a rugosidade do revestimento
}

\author{
Study of the tribological behavior of the \\ Babbitt alloy - steel ABNT 1045 pair \\ when varied thickness and roughness \\ of the coating
}

Rafael Martins Ribeiro ${ }^{12}$, Marcelo Araujo Câmara ${ }^{1}$

\author{
${ }^{1}$ Departamento de Engenharia Mecânica - DEMEC - Universidade Federal de Minas Gerais - UFMG, Av. Antônio \\ Carlos, 6627, CEP: 31270-901, Pampulha, Belo Horizonte, MG, Brasil. \\ ${ }^{2}$ Instituto Federal de Minas Gerais - Campus Ipatinga - Rua Maria Silva, 125, CEP: 35164-261, Veneza, Ipatinga , MG, \\ Brasil. \\ e-mail: rafael.ribeiro@ifmg.edu.br; marcelocamara@demec.ufmg.br
}

\section{RESUMO}

O Babbitt, também conhecido como metal patente ou metal branco é uma liga macia muito utilizada em mancais de deslizamento que trabalham em contato com aço, e tem como elementos de base estanho ou chumbo, além de compostos intermetálicos formados geralmente por antimônio e cobre. O presente trabalho buscou avaliar a influência dos parâmetros rugosidade e espessura do revestimento no comportamento tribológico da liga quando em contato com o aço ABNT 1045. Foram realizados ensaios tribológicos de pino sobre disco, utilizando pinos de aço ABNT 1045 e corpos de prova de aço revestidos com Babbitt simulando o contato de um eixo sobre um mancal revestido com Babbitt. A rugosidade e a espessura do revestimento foram variadas em três níveis, com o intuito de observar o comportamento em relação ao atrito e ao desgaste com a modificação destas variáveis. Nos ensaios que utilizaram corpos de prova com as menores rugosidades dentro da faixa analisada, ocorreu um aumento de $0,05 \pm 0,02$ para 0,46 $\pm 0,06$ no coeficiente de atrito quando se elevou a espessura de revestimento de $0,45 \pm 0,07 \mathrm{~mm}$ para $1,08 \pm 0,17 \mathrm{~mm}$. O maior coeficiente de atrito foi observado no ensaio do corpo de prova com maior espessura de revestimento $(1,08 \pm 0,17 \mathrm{~mm}) \mathrm{e}$ menor rugosidade $(0,47 \pm 0,01 \mu \mathrm{m})$, o maior desgaste foi registrado no ensaio com o corpo de prova de maiores espessura de revestimento e rugosidade $(1,08 \pm 0,17 \mathrm{~mm}$ e $1,29 \pm 0,20 \mu \mathrm{m}$, respectivamente) e o menor desgaste e coeficiente de atrito foram obtidos pelo ensaio realizado no corpo de prova com menor rugosidade $(0,43 \pm 0,03 \mu \mathrm{m})$ e espessura de revestimento média $(0,45 \pm 0,07 \mathrm{~mm})$.

Palavras-chave: Babbitt, aço ABNT 1045, rugosidade, espessura do revestimento, pino sobre disco.

\begin{abstract}
Babbitt, also known as patent metal or white metal, is a soft alloy widely used in sliding bearings that work in contact with steel, and has as base elements tin or lead, as well as intermetallic compounds usually formed by antimony and copper. The aim of this work was to evaluate the influence of the parameters roughness and thickness of the coating on the tribological behavior of the alloy when in contact with steel ABNT 1045 . Tribological pin-on-disk tests were performed using ABNT 1045 steel pins and Babbitt-coated steel test specimens simulating the contact of a shaft on a Babbitt-coated bearing. The roughness and the thickness of the coating were varied in three levels, in order to observe the behavior in relation to the friction and the wear with the modification of these variables. In the tests that used test specimens with the smallest roughness within the analyzed range, an increase of $0.05 \pm 0.02$ to $0.46 \pm 0.06$ in the friction coefficient occurred when the coating thickness was raised from $0.45 \pm 0.07 \mathrm{~mm}$ for $1.08 \pm 0.17 \mathrm{~mm}$. The highest coefficient of friction was observed in the test of the specimen with a higher coating thickness $(1.08 \pm 0.17 \mathrm{~mm})$ and lower roughness $(0.47 \pm 0.01 \mu \mathrm{m})$, the highest wear was recorded in the test with the highest coating thickness and roughness $(1.08 \pm 0.17 \mathrm{~mm}$ and $1.29 \pm 0.20 \mu \mathrm{m}$, respectively) and the lowest wear and friction coefficient
\end{abstract}


were obtained by the test performed in the specimen with the least roughness $(0.43 \pm 0.03 \mu \mathrm{m})$ and medium coating thickness $(0.45 \pm 0.07 \mathrm{~mm})$.

Keywords: Babbitt, ABNT steel 1045, roughness, coating thickness, pin-on-disk.

\section{INTRODUÇ̃̃O}

Uma liga que contém estanho, antimônio, cobre e chumbo é indicada para uma série de aplicações, devido ao seu excelente comportamento em atrito, a uma resistência à corrosão razoavelmente boa e ao seu baixo custo. Esta liga combina boa capacidade de carga, baixo desgaste, bom comportamento no running-in e trabalha bem em situações emergenciais, como ausência da quantidade adequada de lubrificante [1].

Inúmeros equipamentos industriais utilizam mancais revestidos por esta liga, conhecida como Babbitt, podendo-se citar compressores, bombas, turbinas, ventiladores, eixos de transmissão, geradores, entre outros [2,3]. A vida útil destes mancais depende de ganhos na resistência ao desgaste e confiabilidade dos componentes, para que haja uma redução na demanda de recuperação e fabricação para reposição.

O Babbitt, também conhecido como metal patente ou metal branco, foi patenteado por Isaac Babbitt em 1839, na sua fórmula original composta por $89 \%$ Sn, $9 \%$ Sb e $2 \%$ Cu [4]. Hoje, além das ligas à base de estanho (com composições diversas além da original) existem ligas à base de chumbo e ligas à base de estanho e chumbo. De maneira que as ligas à base de estanho, mesmo sendo mais caras são as mais utilizadas em função das suas características, como boa resistência à corrosão, fácil ligação, pequena tendência à segregação e alta condutividade térmica [5-8]. Ademais, as ligas à base de estanho também possuem melhor resistência ao desgaste, maior suporte de carga normal e são menos frágeis [9].

Diante do exposto, se torna atrativo o estudo do comportamento tribológico desta liga, por meio da análise dos parâmetros de acabamento da superfície. Para tanto, neste estudo foi proposta à avaliação de dois parâmetros de uma liga Babbitt, quais sejam a rugosidade e espessura de revestimento, trabalhando em contato com o aço ABNT 1045, de forma a simular o contato existente entre um eixo rotativo e o revestimento de um mancal de deslizamento, quando em serviço.

Portanto, o trabalho teve como objetivo analisar o comportamento de atrito e desgaste de um revestimento de Babbitt realizado por aspersão térmica, quando colocado em contato com o aço ABNT 1045 por meio de ensaio de pino sobre disco, nos quais foram combinados diferentes valores de rugosidade e espessura de revestimento para a liga.

\section{REVISÃO BIBLIOGRÁFICA}

\subsection{Composição química do Babbitt}

O Babbitt à base de estanho é uma liga heterogênea composta por uma matriz dúctil, que é uma solução sólida de antimônio e cobre em estanho, e duas outras fases formadas por compostos intermetálicos mais duros que a matriz [6,7]. Sendo uma destas uma fase formada por grandes cubos duros de estanho e antimônio $(\mathrm{SnSb})$, e a outra composta por cobre e estanho $(\mathrm{CuSn})$ em formato de estrelas ou agulhas de acordo com a quantidade presente de cada um destes dois elementos químicos [7,10].

Por sua vez, o Babbitt à base de chumbo, que não é tão utilizado atualmente principalmente por razões ambientais, possui na maioria de suas composições, além de chumbo, estanho, antimônio e arsênio (que fortalece a liga principalmente em altas temperaturas). Geralmente é formada uma matriz de chumbo, antimônio e estanho que incorpora cubos de $\mathrm{SnSb}$. Eles são menos susceptíveis à fadiga térmica e mecânica em relação aos Babbitts à base de estanho, porém têm menor resistência à corrosão [11,12].

Tanto o Babbitt à base de estanho quanto à base de chumbo podem ser depositados em filmes muito finos sobre substratos de aço de mancais de deslizamento e permitem a incrustação de pequenas partículas de desgaste geradas durante o contato [13]. Ligas Babbitt à base de estanho apesar de possuírem baixa resistência à fadiga são consideradas a melhor escolha para altas velocidades e baixas cargas, e também para mancais de difícil lubrificação, além de possuírem uma relativamente superior resistência à corrosão quando comparadas às ligas à base de chumbo, em função das agulhas de cobre-estanho presentes em sua microestrutura $[8$, 14].

\subsection{Aspectos tribológicos gerais}

As ligas de metal branco geralmente são selecionadas preferencialmente como materiais de mancais deslizantes porque além de apresentar uma alta capacidade de incorporação de partículas geradas no atrito (o que 
reduz o desgaste do eixo), elas são incompatíveis metalurgicamente com o material de fabricação de eixos rotativos, que geralmente são de aço com baixo teor de carbono $[8,13]$. Isto é benéfico, pois metais dissimilares tendem a ter menor desgaste adesivo no contato entre suas asperezas quando comparado com metais similares [12].

A resistência ao desgaste pode ser considerada a principal propriedade de um material utilizado em mancais de deslizamento [15]. Mesmo assim, geralmente, utilizam-se materiais para fabricação de buchas e casquilhos de mancais ou para revesti-los, que possuam menor resistência ao desgaste em relação ao material do eixo. Isto é preferível, pois promove economia, uma vez que o eixo normalmente é o elemento mais caro entre os dois [16].

Em relação à lubrificação, o Babbitt deve trabalhar preferencialmente sob regime de lubrificação hidrodinâmica ou hidrostática, evitando-se lubrificação mista, limítrofe ou contato à seco, pois estas poderão conduzi-lo a falhar rapidamente devido à sua baixa temperatura de fusão [13].

Todos os regimes de lubrificação ocorrem nos mancais durante a parada, a partida ou o funcionamento dos equipamentos, de maneira que quanto maior a velocidade de deslizamento, maior a tendência à formação de um regime de lubrificação hidrodinâmica e consequentemente maior a redução do coeficiente de atrito. Isto ocorre até certo valor de velocidade, pois caso se eleve ainda mais a velocidade, existe a tendência de aumento do atrito devido à perda de viscosidade do lubrificante cisalhado em função do aumento de temperatura [13].

\subsection{Espessura e rugosidade do revestimento}

O estudo da rugosidade e da espessura de revestimento de camadas de Babbitt é importante para diversas aplicações industriais [17]. De uma maneira geral, pode-se dizer com relação às duas variáveis estudadas neste trabalho que, caso a espessura do revestimento apresente valores muito baixos, ela tende a não conseguir evitar o contato entre as asperezas do substrato e do material colocado em contato com o revestimento, promovendo a elevação do valor do coeficiente de atrito. Caso ocorra o contrário, que é a utilização de um revestimento com uma espessura muito elevada, também deve acontecer o aumento do coeficiente de atrito, isso se dá porque o material do revestimento começa a ser solicitado para auxiliar no suporte da carga normal, sendo que ele não possui resistência mecânica suficiente para esta aplicação [12].

A rugosidade geralmente segue a mesma tendência. Em valores muito baixos provoca a elevação do coeficiente de atrito, devido a forte influência da adesão que ocorre em função de uma grande área real de contato, e quando aparece em valores muito altos também provoca um alto coeficiente de atrito, devido à ocorrência de deformação plástica severa dos picos e desgaste abrasivo [12].

Camadas finas de Babbitt embora não apresentem boa capacidade de incorporação de partículas duras em relação à buchas espessas do mesmo material, apresentam melhor resistência à fadiga, pois, as camadas mais espessas de revestimento tendem a trincar com mais facilidade e a liberar pequenas partículas conforme ocorre o esforço cíclico [13,18].

O uso de revestimentos de Babbitt tem a sua espessura limitada até certo valor de carga, uma vez que para aplicações mais exigentes utiliza-se revestimentos cada vez mais finos da liga aplicada sobre substrato mais resistente [12]. ALMEIDA [18] afirma que camadas de Babbitt com espessuras inferiores a 0,1 $\mathrm{mm}$ de espessura possibilitam uma vida útil consideravelmente maior ao componente, pois promovem grande resistência à fadiga e a compressão.

Porém, quanto mais fina se torna a película de revestimento aplicada, menor a capacidade da liga de suportar desalinhamento do eixo e o contato com partículas abrasivas, e de acomodá-las. Sendo nestes casos indicado o uso de materiais de maior resistência mecânica [12].

JI e CHEN [19] encontraram profundidades de desgaste de 70 e $200 \mu \mathrm{m}$ em ensaios de deslizamento realizados com Babbitt. Estes são valores que podem ultrapassar determinadas espessuras de revestimento utilizadas e provocar o contato entre o eixo e o substrato do mancal, de maneira a potencializar o desgaste. Desta forma, este é outro fator a ser considerado para se evitar o uso de revestimentos extremamente finos.

O revestimento também deve ter ajustado o seu valor de rugosidade, pois influencia diretamente no comportamento tribológico dos materiais em contato. Tanto a geometria quanto as dimensões dos picos interferem no desempenho dos mancais. Superfícies muito rugosas, por exemplo, podem perder capacidade de carga [20]. LASHIN et al. [6] e CHIAVERINI [14] por sua vez, consideram um revestimento cuja superfície tenha menor rugosidade como melhor para aplicações em mancais, pois a penetração e remoção de partículas tende a ser menor. Porém, para HUTCHINGS e SHIPWAY [12] e NORTON [13] a rugosidade provoca um aumento da taxa de desgaste e do coeficiente de atrito quando aparece com valores muito baixos ou muito 
altos, exigindo assim que se busque um valor intermediário aceitável de acordo com os parâmetros de carga normal e velocidade de deslizamento utilizados.

HUTCHINGS e SHIPWAY [12] exibem uma relação do coeficiente de atrito e da taxa de desgaste com a rugosidade e a espessura do filme de lubrificante formado em um contato de deslizamento metálico lubrificado, Figura 1. É possível perceber que tanto com o aumento da espessura do filme lubrificante quanto com a redução da rugosidade existe uma tendência inicial de redução do coeficiente de atrito e da taxa de desgaste, além de uma transição no tipo de lubrificação, passando de limítrofe para mista e tendendo a um regime hidrodinâmico. Há uma elevação posterior no coeficiente de atrito caso a rugosidade reduza ainda mais ou a espessura do filme continue sendo aumentada, possivelmente em função de uma grande adesão em virtude da baixíssima rugosidade da superfície (que tende a aumentar muito a área real de contato) e da grande espessura do filme lubrificante (maior influência da viscosidade).

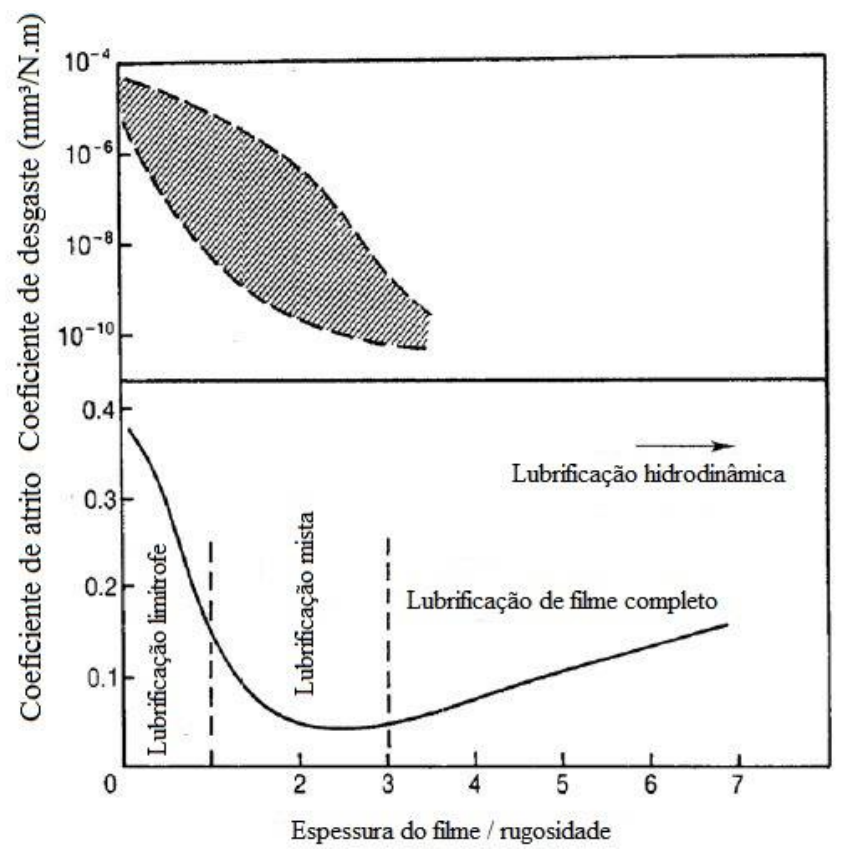

Figura 1: Regimes de lubrificação, desgaste e coeficiente de atrito no deslizamento lubrificado de metais, em função da relação entre a espessura do filme e a rugosidade da superfície [12].

De acordo com a curva de Stribeck, o coeficiente de atrito apresenta uma variação conforme são modificadas a pressão de contato, a velocidade e a viscosidade do lubrificante. Esta curva tem comportamentos diferentes quando modificada a rugosidade da superfície de contato, de acordo com a equação 1, que determina o número de Shipper. S é o número de Shipper, v é a viscosidade, v é a velocidade, $\mathrm{P}$ é a pressão de contato e R é a rugosidade [11].

$$
S=\frac{v \cdot v}{P \cdot R}
$$

Observa-se que em altos valores de rugosidade existe a tendência de contato entre as asperezas dos corpos atritados. Portanto há necessidade de se elevar a velocidade ou reduzir a pressão de contato para se obter um menor coeficiente de atrito em função da modificação do regime de lubrificação, passando de limítrofe para misto ou de misto para de filme completo. É sugerido que existe uma diferença de valores de coeficiente de atrito para uma mesma carga, velocidade e viscosidade do lubrificante quando se varia a rugosidade no regime de lubrificação misto, Figura 2. 


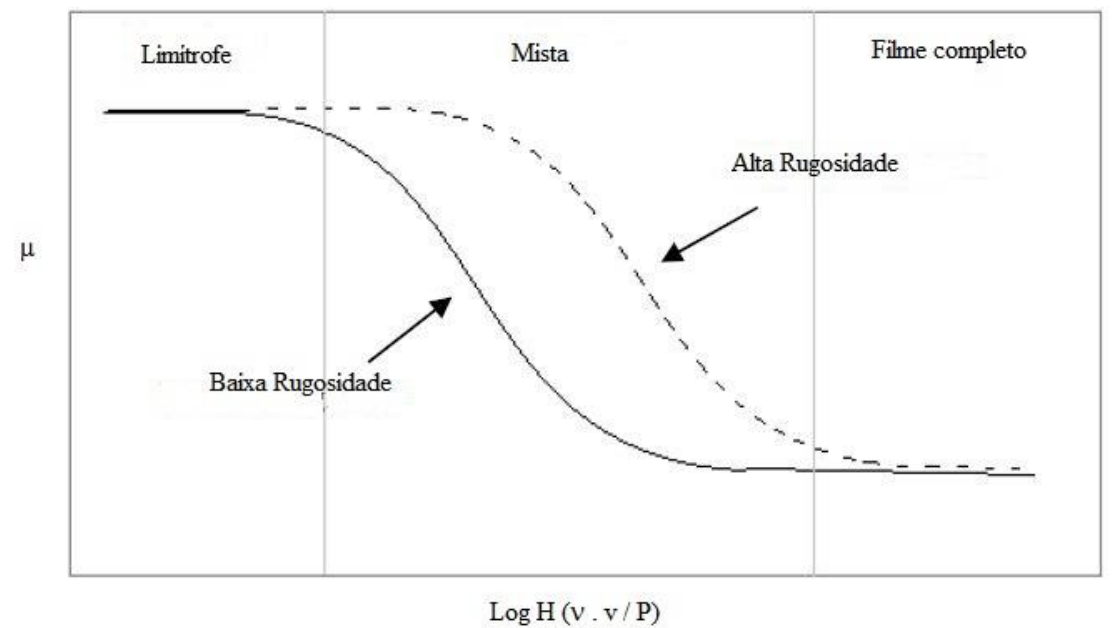

Figura 2: Influência da rugosidade na curva de Stribeck analisada pelo Log de H (número de Hersey) X coeficiente de atrito [11].

\section{MATERIAIS E MÉTODOS}

\subsection{Materiais}

O equipamento utilizado para os ensaios tribológicos de pino sobre disco foi o tribômetro Microtest modelo $\mathrm{MT} / 60 / \mathrm{NI}$.

Um microscópio eletrônico de varredura JEOL JSM-6360LV foi usado para auxiliar na caracterização da amostra. A rugosidade linear dos corpos de prova (CP's) foi medida com um rugosímetro digital portátil INSIZE modelo ISR-16.

Para a medição de microdureza foi utilizado o equipamento para ensaios de microdureza Mitutoyo MVK-H1 e para a perfilometria utilizou-se o perfilômetro 3D HOMMELWERKE modelo T8000.

Os pinos utilizados nos ensaios tribológicos são do tipo topo esférico com 6 mm de diâmetro, fabricados em aço ABNT 1045.

\subsection{Métodos}

Os corpos de prova passaram por um processo de fresamento frontal para que se tivesse a espessura de revestimento nos valores desejados e apenas a rugosidade intermediária da face revestida com Babbitt foi alcançada pelo processo de fresamento, os outros dois valores foram obtidos por preparação posterior por meio de lixamento.

Os CP's que tiveram a rugosidade modificada após o fresamento foram lixados em uma politriz semiautomática Arotec Aropol VV cuja rotação varia de 50 a 600 rpm. Foram utilizadas lixas com granulometria de 180 a 1200 mesh para atingirem os valores de rugosidade desejados. Portanto foi realizada a combinação de três valores de rugosidade e três valores de espessura, Tabela 1.

A medição da rugosidade Ra dos CP's foi realizada de acordo com a norma NBR ISO 4287 [21] e a medição de microdureza, por sua vez, seguiu a norma ASTM E384 [22], na qual foram realizadas 4 medições em cada uma das fases presentes no material.

Os ensaios de pino sobre disco foram conduzidos com lubrificação mista, utilizando o óleo V SAE 40 ISO, indicado para ser utilizado entre outras aplicações, em mancais de deslizamento. Foi utilizada uma velocidade relativamente baixa, e, portanto o ensaio alternou em momentos de lubrificação de filme completo (possivelmente elasto-hidrodinâmica em função do contato pontual do pino com o disco) e em momentos de lubrificação limítrofe, na qual houve o contato de asperezas em determinados pontos. Todos os ensaios foram conduzidos de acordo com os parâmetros descritos na Tabela 2.

A medição do perfil de desgaste das pistas resultantes de ensaios de pino sobre disco é um meio para determinar com exatidão a forma final das superfícies desgastadas e desta forma ter embasamento para calcular o volume de material perdido em decorrência do desgaste [23]. 
Tabela 1: Corpos de prova utilizados nos ensaios pino sobre disco.

\begin{tabular}{c|l|l}
\hline CORPO DE PROVA & $\begin{array}{l}\text { ESPESSURA DE } \\
\text { REVESTIMENTO }\end{array}$ & $\begin{array}{l}\text { RUGOSIDADE } \\
\text { MÉDIA - RA }\end{array}$ \\
\hline 1 & $0,23 \pm 0,05 \mathrm{~mm}$ & $0,45 \pm 0,02 \mu \mathrm{m}$ \\
\hline 2 & $0,23 \pm 0,05 \mathrm{~mm}$ & $0,69 \pm 0,02 \mu \mathrm{m}$ \\
\hline 3 & $0,23 \pm 0,05 \mathrm{~mm}$ & $1,24 \pm 0,20 \mu \mathrm{m}$ \\
\hline 4 & $0,45 \pm 0,07 \mathrm{~mm}$ & $0,43 \pm 0,03 \mu \mathrm{m}$ \\
\hline 5 & $0,45 \pm 0,07 \mathrm{~mm}$ & $0,71 \pm 0,03 \mu \mathrm{m}$ \\
\hline 6 & $0,45 \pm 0,07 \mathrm{~mm}$ & $1,17 \pm 0,18 \mu \mathrm{m}$ \\
\hline 7 & $1,08 \pm 0,17 \mathrm{~mm}$ & $0,47 \pm 0,01 \mu \mathrm{m}$ \\
\hline 8 & $1,08 \pm 0,17 \mathrm{~mm}$ & $0,74 \pm 0,13 \mu \mathrm{m}$ \\
\hline 9 & $1,08 \pm 0,17 \mathrm{~mm}$ & $1,29 \pm 0,20 \mu \mathrm{m}$ \\
\hline
\end{tabular}

Tabela 2: Variáveis adotadas nos ensaios tribológicos.

\begin{tabular}{l|l|l|l}
\hline $\begin{array}{l}\text { CONDIÇÃO DE } \\
\text { LUBRIFICAÇÃO }\end{array}$ & $\begin{array}{l}\text { VELOCIDADE DE } \\
\text { DESLIZAMENTO }\end{array}$ & $\begin{array}{l}\text { CARGA NOR- } \\
\text { MAL }\end{array}$ & TEMPO \\
\hline Lubrificação mista & $0,82 \mathrm{~m} / \mathrm{min}$ & $1 \mathrm{~N}$ & $10 \mathrm{~min}$ \\
\hline
\end{tabular}

Quando somente o disco apresenta desgastes significativos, é possível determinar a perda volumétrica da amostra pela equação 2, na qual $\mathrm{P}_{\mathrm{V}}$ é a perda volumétrica do disco, $\mathrm{r}_{\mathrm{t}}$ é o raio da trilha de desgaste, $b_{t}$ é a largura da trilha de desgaste e $r_{p}$ é o raio do topo esférico do pino. Portanto este foi o método utilizado para calcular a perda volumétrica. Caso tivesse ocorrido desgaste significativo em ambos (pino e disco), seria indicada a medição do perfil de desgaste nos dois por perfilometria [23].

$$
P_{V}=\frac{r_{t \times b_{t}}}{6 \times r_{p}}
$$

\section{RESULTADOS E DISCUSSÃO}

\subsection{Caracterização}

$\mathrm{O}$ aspecto geral da liga Babbitt utilizada e a sua morfologia são apresentadas na Figura 3. A liga é formada pelas fases $\alpha-\mathrm{Pb}$ (região branca), $\beta$-Sn na região cinza escura, grãos de $\mathrm{SnSb}$ na parte cinza claro e pelas agulhas possivelmente de $\mathrm{CuSn}$, que são facilmente identificadas em função do seu formato característico.

Foi observada por meio de análise por espectroscopia de dispersão de energia por raios-X (EDS) a possível presença de inclusões de óxido de alumínio na amostra, que provavelmente se formaram durante a deposição do revestimento. Além disso, observou-se a existência de uma região dendrítica que se formou possivelmente em virtude do rápido resfriamento e solidificação da liga durante o processo de deposição. A formação de cristais diminui com o aumento da taxa de resfriamento, o que pode promover o surgimento de dendritas no lugar de cubos, melhorando desta forma a tenacidade da liga sem alterar a sua resistência [24]. Também foi possível perceber o pequeno, porém existente surgimento de poro. 


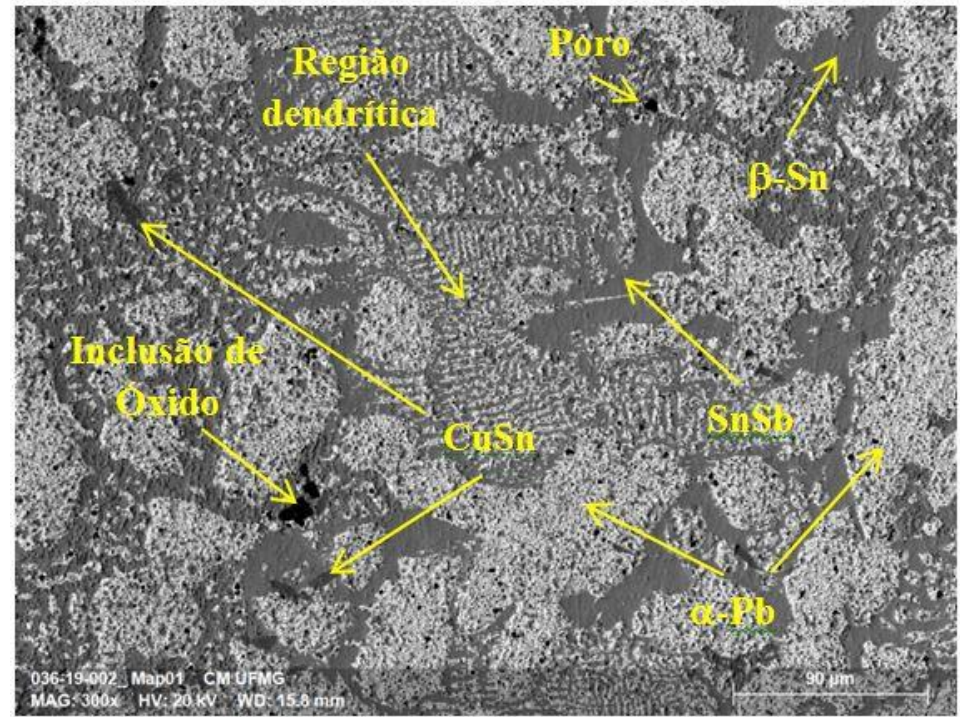

Figura 3: Morfologia da liga Babbitt utilizada como revestimento.

A microdureza média observada em cada uma das regiões tanto do Babbitt quanto do aço é apresentada na Tabela 3. Não foi possível mensurar a microdureza da fase em formato de agulhas (CuSn), pois estava fora da capacidade do microdurômetro. Percebe-se pelos valores de microdureza que o elemento mais duro do Babbitt é o composto intermetálico $\mathrm{SnSb}$, enquanto o mais macio é a matriz de chumbo. Não houve variação considerável na microdureza dos compostos intermetálicos conforme se modificou a profundidade de medição na amostra de perfil.

Tabela 3: Microdureza dos componentes do Babbitt e do aço.

\begin{tabular}{c|l|l}
\hline MATERIAL & FASE & $\begin{array}{l}\text { MICRODUREZA } \\
(\mathbf{H V})\end{array}$ \\
\hline \multirow{3}{*}{ Babbitt } & $\alpha-\mathrm{Pb}$ & $12,9 \pm 0,3$ \\
\cline { 2 - 3 } & $\beta-\mathrm{Sn}$ & $23,2 \pm 2,7$ \\
\cline { 2 - 3 } & $\mathrm{SnSb}$ & $31,2 \pm 1,4$ \\
\hline \multirow{2}{*}{ Aço } & Ferrita & $182,4 \pm 3,5$ \\
\cline { 2 - 3 } & Perlita & $272,0 \pm 11,5$ \\
\hline
\end{tabular}

\subsection{Coeficiente de atrito}

Os dados de coeficiente de atrito do contato entre o pino de aço ABNT 1045 e o Babbitt revestido sobre o mesmo aço para todos os ensaios realizados são apresentados na Figura 4.

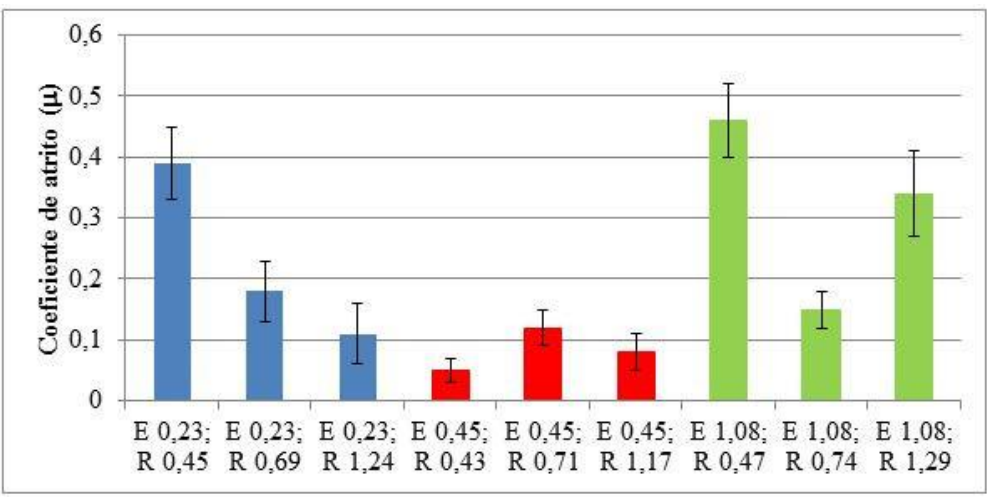

Figura 4: Influência da modificação da rugosidade no coeficiente de atrito dos ensaios de pino sobre disco. 
Pode-se perceber que o ensaio que apresentou o maior coeficiente de atrito foi aquele em que o corpo de prova utilizado possuía a maior espessura de revestimento $(1,08 \pm 0,17 \mathrm{~mm})$ e a menor rugosidade $\mathrm{Ra}$ $(0,47 \pm 0,01 \mu \mathrm{m})$. Ele apresentou coeficiente de atrito no valor de 0,46 $\pm 0,06$, enquanto o menor valor de coeficiente de atrito foi registrado pelo ensaio que possuía a espessura intermediária $(0,45 \pm 0,07 \mathrm{~mm})$ e menor rugosidade $\mathrm{Ra}(0,43 \pm 0,03 \mu \mathrm{m})$. Entre os três maiores coeficientes de atrito encontram-se dois corpos de prova com a maior espessura de revestimento.

Observa-se que para a menor espessura de revestimento o coeficiente de atrito tendeu a cair conforme se elevou a rugosidade dos corpos de prova revestidos. De acordo com ZHANG et al. [25], a maior presença de vales na superfície mais rugosa proporciona o armazenamento de óleo e um menor coeficiente de atrito.

A espessura intermediária de revestimento $(0,45 \pm 0,07 \mathrm{~mm})$ exibiu um maior coeficiente de atrito para a rugosidade intermediária $(0,71 \pm 0,03 \mu \mathrm{m})$, seguido pela maior rugosidade $(1,17 \pm 0,18 \mu \mathrm{m})$ e menor rugosidade $(0,43 \pm 0,03 \mu \mathrm{m})$, respectivamente.

Por sua vez, nos ensaios que utilizaram os corpos de prova com maior espessura de revestimento $(1,08$ $\pm 0,17 \mathrm{~mm}$ ), o maior valor de coeficiente de atrito foi mensurado no ensaio com rugosidade de $0,47 \pm 0,01$ $\mu \mathrm{m}$, seguido pela rugosidade de 1,29 $\pm 0,20 \mu \mathrm{m}$ e por último a rugosidade de $0,74 \pm 0,13 \mu \mathrm{m}$. O que indica uma variação semelhante à teoria apresentada por HUTCHINGS e SHIPWAY [12], na qual o coeficiente de atrito tende a valores maiores quando a rugosidade do corpo de prova possui valores maiores e menores dentro da faixa trabalhada.

Em relação à influência da espessura de revestimento nos três diferentes níveis de rugosidade observase que para os menores valores de rugosidade, foi obtido um valor de coeficiente de atrito extremamente baixo de $0,05 \pm 0,02$ para a espessura intermediária $(0,45 \pm 0,07 \mathrm{~mm})$, seguido por um coeficiente de atrito de $0,39 \pm 0,06$ para a espessura de revestimento de $0,23 \pm 0,05 \mathrm{~mm}$ e $0,46 \pm 0,06$ para a maior espessura de revestimento $(1,08 \pm 0,17 \mathrm{~mm})$, Figura 5 . No caso da rugosidade intermediária a espessura de 0,45 $\pm 0,07 \mathrm{~mm}$ também apresentou o menor coeficiente de atrito, porém o segundo menor valor foi registrado pela espessura superior e o maior valor de coeficiente de atrito pertenceu à espessura de 0,23 $\pm 0,05 \mathrm{~mm}$.

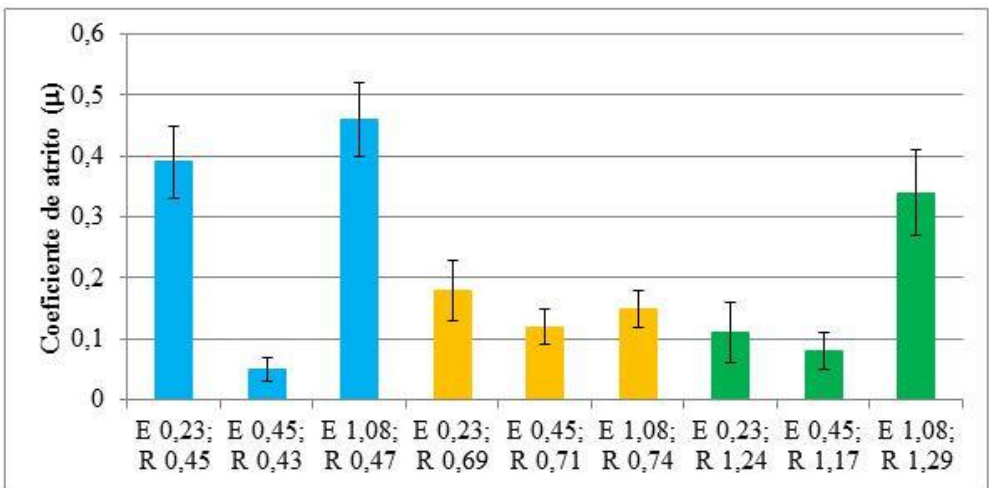

Figura 5: Influência da modificação da espessura do revestimento no coeficiente de atrito dos ensaios de pino sobre disco.

Uma ordem de valores de coeficiente de atrito semelhante à observada para as menores rugosidades também ocorreu para as rugosidades mais elevadas. Desta forma, o menor valor de coeficiente de atrito para esta rugosidade foi da espessura de $0,45 \pm 0,07 \mathrm{~mm}(\mu=0,08 \pm 0,03)$, registrou-se um coeficiente de atrito de $0,34 \pm 0,07$ para a maior espessura de revestimento e um valor intermediário de coeficiente de atrito de 0,11 $\pm 0,05$ refere-se a menor espessura.

Variando-se a espessura de revestimento em qualquer uma das rugosidades utilizadas percebe-se que os valores de coeficiente de atrito tenderam a elevar-se tanto no menor quanto no maior valor. Este é um comportamento semelhante ao que é retratado por HUTCHINGS e SHIPWAY [12], no qual valores menores e maiores de espessura de revestimento tendem a apresentar altos coeficientes de atrito porque há a tendência do contato entre as asperezas do substrato e do pino ou o revestimento tende a começar a suportar carga normal, respectivamente. Para o menor valor de rugosidade houve a maior variação do coeficiente de atrito quando se elevou ou reduziu a espessura de revestimento. 


\subsection{Medição do desgaste}

A medição de desgaste dos ensaios foi realizada pela análise do volume de material perdido pelo corpo de prova dividido pela distância deslizada durante o ensaio de pino sobre disco. A análise por perfilometria permitiu mensurar a largura das pistas de desgaste (que pode ser observada pelos marcadores utilizados pelo software do perfilômetro na Figura 6), para aplicar o valor encontrado na equação 2.

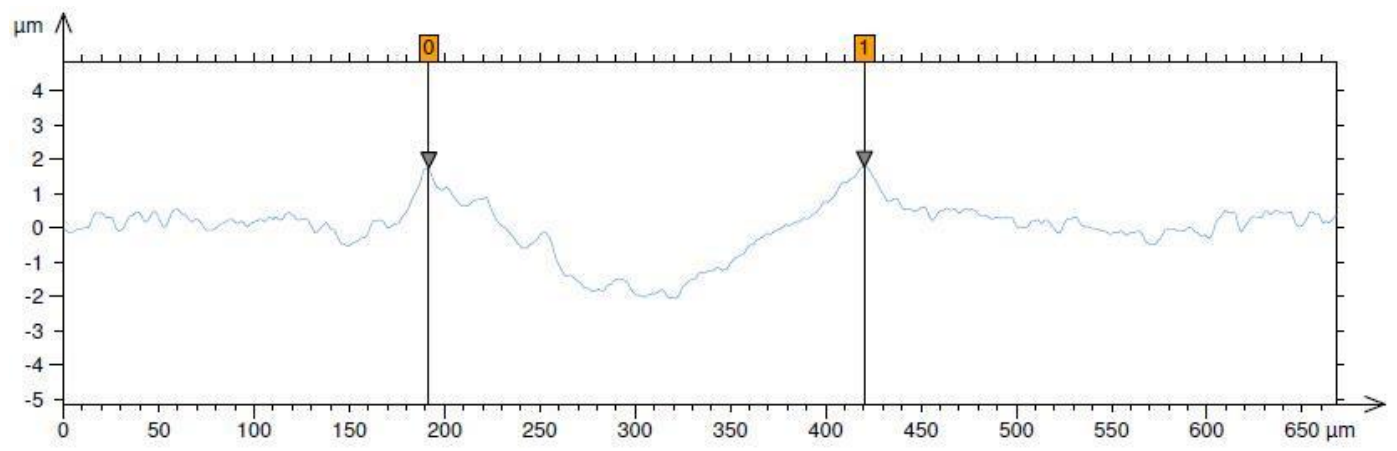

Figura 6: Medição de largura de uma das pistas de desgaste dos ensaios pino sobre disco.

Foi utilizada a metodologia de perda de volume do disco para mensurar o desgaste, pois não houve desgaste considerável no pino de aço, conforme estabelecido por norma [23]. O mapeamento do topo esférico de um dos pinos é apresentado na Figura 7.
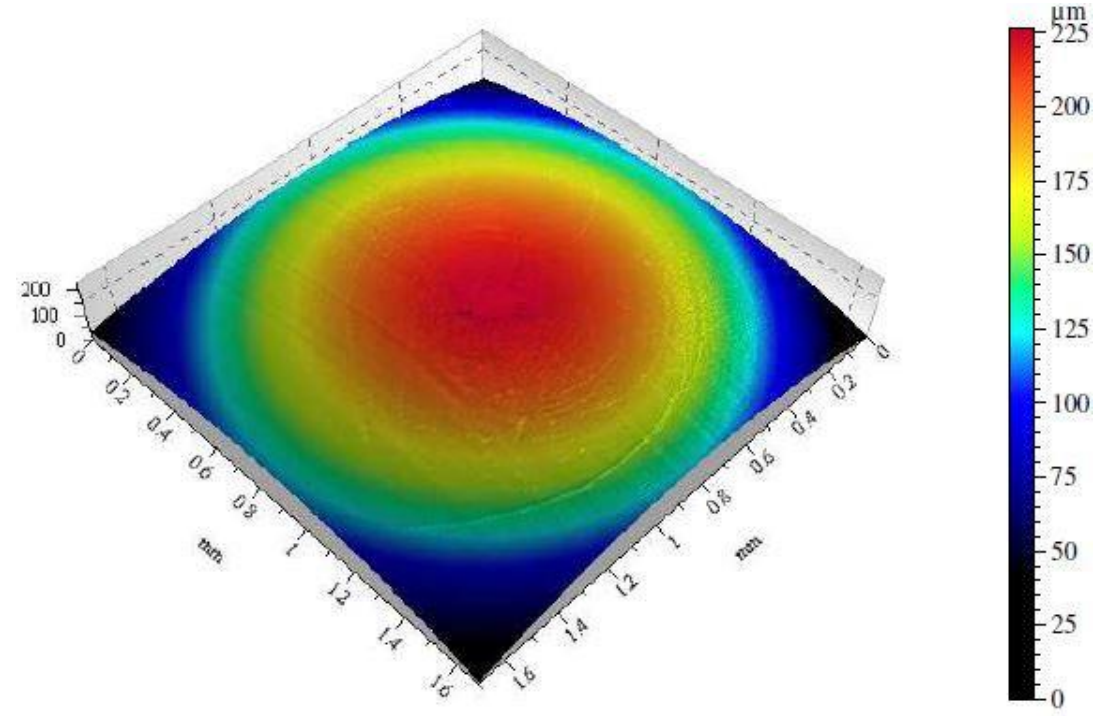

Figura 7: Mapeamento perfilométrico do pino de aço.

O aspecto das pistas de desgaste e os mecanismos de desgaste atuantes, por sua vez, foram analisados por meio de microscopia eletrônica de varredura.

Os resultados de desgaste para todos os ensaios de pino sobre disco são apresentados na Figura 8. 


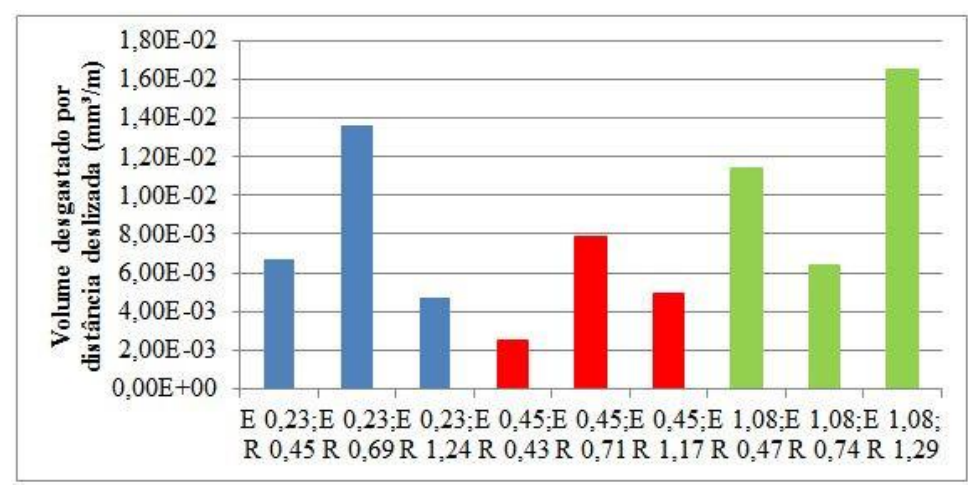

Figura 8: Influência da modificação da rugosidade no volume de desgaste por distância de deslizamento dos ensaios de pino sobre disco.

A figura mostra que os ensaios que envolveram os corpos de prova com maior espessura de revestimento $(1,08 \pm 0,17 \mathrm{~mm})$ e rugosidades $\mathrm{Ra}$ de $1,29 \pm 0,20 \mu \mathrm{m}$ e $0,47 \pm 0,01 \mu \mathrm{m}$, apresentaram o maior e o terceiro maior desgaste, respectivamente. Eles também se posicionaram entre os maiores valores de coeficiente de atrito, alternando somente a ordem em que cada um ficou posicionado (primeiro e terceiro maiores valores).

O menor desgaste foi observado para o ensaio realizado com o corpo de prova que possuía a espessura intermediária $(0,45 \pm 0,07 \mathrm{~mm})$ e rugosidade Ra de 0,43 $\pm 0,03 \mu \mathrm{m}$. Este também foi o ensaio que exibiu o menor coeficiente de atrito de todos.

Os ensaios com espessura de revestimento de 0,23 $\pm 0,05 \mathrm{~mm}$ apresentaram menores valores de desgaste tanto com o menor quanto com o maior valor de rugosidade. Para a espessura intermediária foi observado um comportamento bem parecido com aquele verificado nos ensaios com menor espessura de revestimento, o que se modificou foi somente que o menor desgaste para a espessura de revestimento de $0,45 \pm 0,07$ $\mathrm{mm}$ foi observado para a menor rugosidade, conforme descrito por CHIAVERINI [14], que afirma que o desgaste tende a ser menor em superfícies menos rugosas, enquanto que para a menor espessura de revestimento o menor desgaste ocorreu para a maior rugosidade.

Nos ensaios com espessura de revestimento de $1,08 \pm 0,17 \mathrm{~mm}$ o menor desgaste foi registrado no corpo de prova com rugosidade Ra de $0,74 \pm 0,13 \mu \mathrm{m}$, seguido pelo $\mathrm{CP}$ de rugosidade de $0,47 \pm 0,01 \mu \mathrm{m} \mathrm{e}$ posteriormente pelo CP de rugosidade de $1,29 \pm 0,20 \mu \mathrm{m}$.

Assim como ocorreu com o coeficiente de atrito, os CP's com espessura de revestimento de 1,08 \pm 0,17 $\mathrm{mm}$ foram os únicos que exibiram valores de desgaste maiores quando a rugosidade superficial foi aumentada ou diminuída. Para as outras duas espessuras, o comportamento foi inverso, isto é, o maior valor de desgaste ocorreu para a rugosidade intermediária.

As imagens feitas por microscopia eletrônica de varredura (MEV) de todas as pistas ensaiadas e com ampliação de 500 vezes, podem ser visualizadas na Figura 9. Foram realizadas análises de composição química elementar por EDS no interior das trilhas de desgaste objetivando a identificação das variações de composição química do material ao longo do processo de desgaste. Porém não foram observadas variações significativas. 

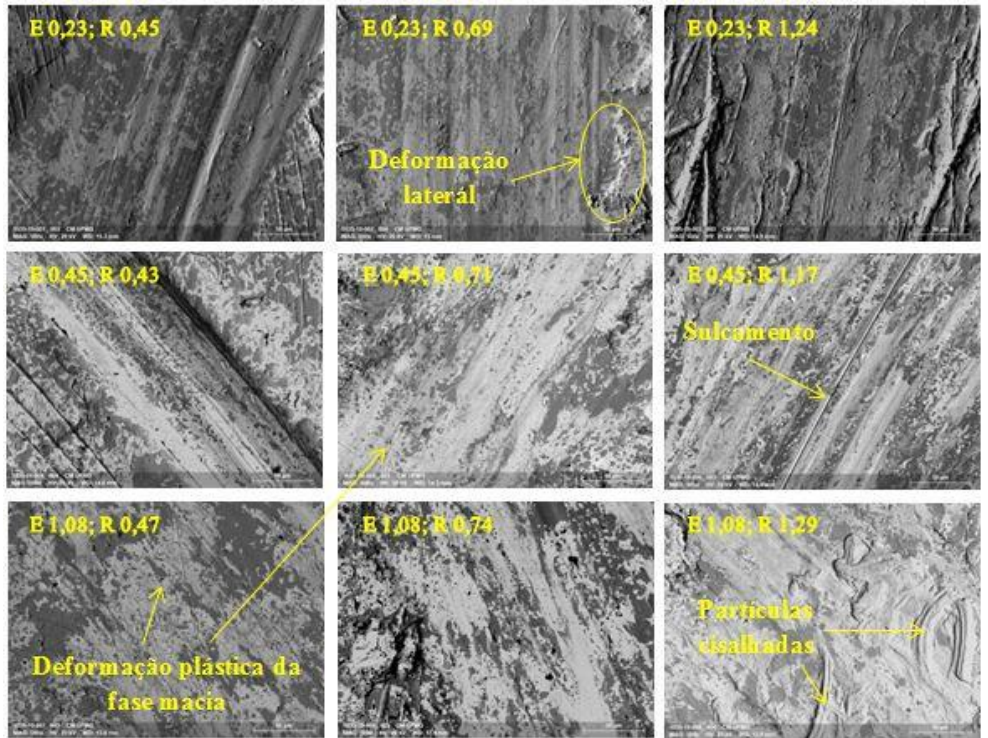

Figura 9: Pistas de desgaste do revestimento de Babbitt sobre um substrato de aço dos ensaios pino sobre disco com ampliações de $500 \mathrm{X}$.

Percebe-se no ensaio E 1,08; R 1,29 que pelo fato deste possuir a maior espessura de revestimento e a maior rugosidade, facilitou a liberação de pequenas partículas de material que foram sulcadas e posteriormente cisalhadas conforme ocorreu o esforço cíclico durante o ensaio e por isso apresentou o mais elevado desgaste, semelhante ao que é descrito por NORTON [13] e ALMEIDA [18]. Segundo HUTCHINGS e SHIPWAY [12] a espessura de Babbitt depositado sobre um substrato tem muito mais influência na resistência à fadiga da liga do que propriamente a sua composição química, e conforme se eleva a espessura de um revestimento de Babbitt menor é a sua resistência à fadiga, e, portanto aparentemente as partículas de desgaste da interface que possuíam baixa resistência ao cisalhamento foram exibidas na forma de chapas laminadas (flake like).

No caso do segundo maior desgaste, a amostra do ensaio E 0,$23 ; \mathrm{R} 0,69$ pelo fato de possuir a menor espessura de revestimento, não liberou partículas de forma facilitada (melhor resistência à fadiga e a fratura frágil), porém apresentou grande deformação lateral e os detritos gerados no desgaste não incorporaram com facilidade na matriz macia exatamente pelo motivo da baixa espessura de revestimento [13]. Ou seja, camadas mais finas de revestimento de Babbitt apresentam baixa capacidade de incorporação.

O ensaio E 1,08; R 0,47 apesar de ter usado a maior espessura de revestimento e ter apresentado o terceiro maior desgaste, não exibiu partículas de desgaste semelhantes àquelas observadas no $\mathrm{CP}$ do ensaio $\mathrm{E}$ 1,$08 ;$ R 1,29 e sim grande deformação plástica de fase macia de chumbo. Muito possivelmente o seu desgaste foi predominantemente adesivo em virtude da baixa rugosidade. Os outros CP's com baixa e média rugosidade também exibiram maior deformação da fase macia de chumbo em função de uma maior adesão.

Com relação aos ensaios que resultaram nos menores desgastes, se encontram como o terceiro e o segundo menor desgaste respectivamente, os CP's dos ensaios E 0,45; R 1,17 e E 0,23; R 1,24. Em ambos é perceptível sulcamento longitudinal nas pistas de desgaste, o que é indicativo de deformação plástica, porém sem grande remoção de material. Além disso, o ensaio E 0,23; R 1,24 possuía uma alta capacidade de suporte de carga normal em virtude da baixa espessura de revestimento (substrato suportando a carga), sem desgaste adesivo (somente deformação devido à alta rugosidade e pequena delaminação).

$\mathrm{O}$ ensaio E 0,45; R 0,43 foi aquele que obteve o menor desgaste entre todos os ensaios realizados e exibiu a pista menos larga. Por possuir baixa rugosidade, a sua superfície possuía menor quantidade de protuberâncias para serem removidas e este fator sobressaiu neste caso em relação à adesão.

A espessura de revestimento da liga influenciou nos ensaios para as três rugosidades utilizadas de três formas distintas, Figura 10. Quando se utilizou os corpos de prova com rugosidade Ra de menores valores, as espessuras menor e maior obtiveram maior volume de desgaste, enquanto a espessura intermediária para esta rugosidade exibiu o menor desgaste de todos os ensaios. 


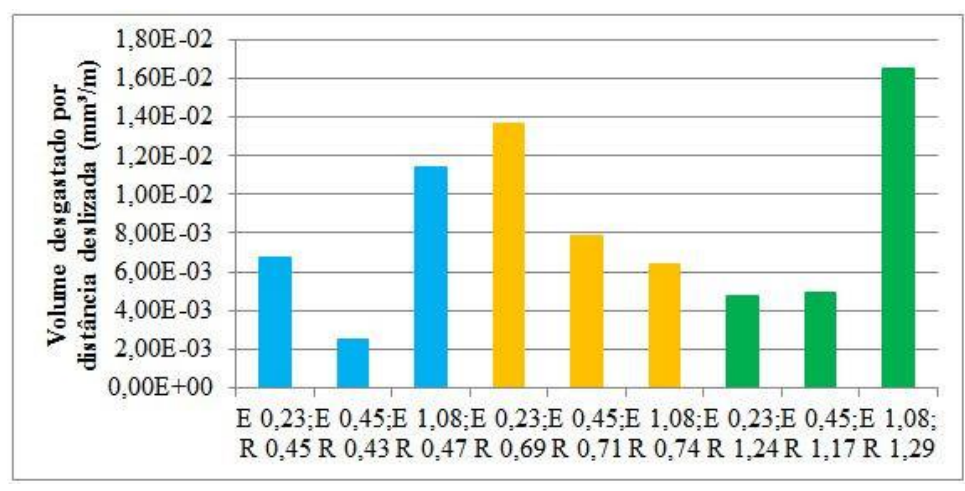

Figura 10: Influência da modificação da espessura do revestimento no volume de desgaste por distância de deslizamento dos ensaios de pino sobre disco.

Ao ensaiar os corpos de prova com rugosidade Ra nos valores intermediários, o volume desgastado nos corpos de prova por distância deslizada durante o ensaio apresentou uma queda conforme se aumentava a espessura do revestimento. Enquanto os corpos de prova com as maiores rugosidades Ra, exibiram uma relação inversa à observada para a rugosidade intermediária, na qual o desgaste aumentou conforme se elevou a espessura do revestimento, destacando-se uma variação muito pequena da espessura de $0,23 \pm 0,05$ para 0,45 $\pm 0,07 \mathrm{~mm}\left(\mathrm{de} 4,75 \times 10^{-3} \mathrm{~mm}^{3} / \mathrm{m}\right.$ para $\left.4,89 \times 10^{-3} \mathrm{~mm}^{3} / \mathrm{m}\right)$ e um aumento considerável para a maior espessura $\left(1,65 \times 10^{-2} \mathrm{~mm}^{3} / \mathrm{m}\right)$.

\subsection{Discussão}

As amostras com maior rugosidade e com espessuras de revestimento menor e intermediária apresentaram valores relativos de desgaste e coeficiente de atrito muito baixos, o que pode ser justificado pelo o que foi encontrado por SEP et al. [20]. Foi verificada a influência da rugosidade no desgaste de mancais de deslizamento e percebeu-se uma melhoria na resistência ao desgaste em superfícies mais rugosas. Isto se deu devido ao fato dos vales agirem como reservatório de óleo, além da ação de remoção das partículas de desgaste das zonas de contato, pois as mesmas tenderam a se deslocar para os vales, o que diminuiu a ocorrência de atrito de três corpos. Também se pode considerar a redução do desgaste adesivo e do atrito estático na partida do movimento, além do aumento do suporte de carga normal propiciados por uma maior rugosidade [26, 27].

Por outro lado, o ensaio que utilizou o disco que possuía o revestimento com maiores espessura e rugosidade exibiu o maior desgaste de todos. Isto pode ser explicado pelo fato do revestimento ser submetido ao suporte da carga normal incidente, quando aparece em espessuras elevadas [12]. Além disso, sabe-se que a presença de chumbo na liga em camadas de revestimento mais espessas, reduz a sua capacidade de carga.

Nos ensaios nos quais os pinos de aço deslizaram sobre os CP's com rugosidade de revestimento com os menores valores, o coeficiente de atrito tendeu a se elevar, apresentando os maiores valores para os ensaios realizados sobre os CP's com maior espessura e menor espessura de revestimento, respectivamente. Isso pode ser justificado pelo grande aumento da área real de contato que ocorre em virtude da baixa altura das asperezas e propiciou grande atrito adesivo. Por sua vez o CP com a menor rugosidade e com espessura intermediária não seguiu esta tendência, possivelmente porque neste caso a espessura influenciou de forma mais considerável, e o coeficiente de atrito foi menor de acordo com o que é descrito na teoria descrita por HUTCHINGS e SHIPWAY [12] para estes casos, e está em conformidade com os resultados de coeficiente de atrito apresentados (maiores coeficientes de atrito para as espessuras maiores e menores de revestimento).

Quando se analisa as amostras com maior espessura de revestimento, somente aquela que possui rugosidade intermediária apresentou valores mais baixos de coeficiente de atrito e de volume de desgaste, enquanto as amostras espessas e com rugosidade do revestimento com o maior e o menor valor situaram-se entre os maiores valores de coeficiente de atrito e desgaste, o que também segue aquilo que a teoria de HUTCHINGS e SHIPWAY [12] traz sobre a influência da rugosidade no coeficiente de atrito e desgaste (ambos tendem a aumentar com a redução ou aumento da mesma) e sobre a espessura de revestimento (quanto maior a espessura do filme de revestimento, maior a tendência a este começar a ser solicitado no suporte da carga normal e consequentemente maior o coeficiente de atrito).

Nos ensaios pino sobre disco que foram realizados utilizando discos que possuem revestimento com menor espessura, foi observado que conforme houve aumento na rugosidade, o coeficiente de atrito reduziu, comportamento contrário ao apresentado por EKLUND [11] em relação à curva de Stribeck no regime de 
lubrificação mista.

\section{CONCLUSÕES}

A análise dos resultados dos ensaios de pino sobre disco realizados com pinos de aço ABNT 1045 sobre corpos de prova de aço revestidos com Babbitt nos quais foram variadas a rugosidade e a espessura do revestimento permite concluir:

- O coeficiente de atrito do ensaio que utilizou o CP com espessura de revestimento de 1,08 $\pm 0,17$ $\mathrm{mm}$ e rugosidade Ra de $0,47 \pm 0,01 \mu \mathrm{m}$ foi cerca de 9 vezes maior em relação ao ensaio com o CP de $0,45 \pm 0,07 \mathrm{~mm}$ de espessura de revestimento e com a rugosidade $\mathrm{Ra}$ de $0,43 \pm 0,03 \mu \mathrm{m}$. Sendo inclusive este primeiro, o ensaio que apresentou o maior coeficiente de atrito entre todos os ensaios, e o segundo o ensaio que apresentou os menores coeficiente de atrito e desgaste.

- A redução do coeficiente de atrito foi de $77 \%$ quando foi diminuída a espessura de revestimento de $1,08 \pm 0,17 \mathrm{~mm}$ para $0,45 \pm 0,07 \mathrm{~mm}$ nos ensaios envolvendo os corpos de prova com as maiores rugosidade $\mathrm{Ra}$ dentro da faixa analisada $(1,29 \pm 0,20 \mu \mathrm{m}$ e $1,17 \pm 0,18 \mu \mathrm{m}$, respectivamente).

- A variação do desgaste não foi significativa entre os ensaios com os corpos de prova com rugosidade Ra de maiores valores e espessuras de revestimento de $0,23 \pm 0,05$ e $0,45 \pm 0,07 \mathrm{~mm}$, porém aumentou cerca de 3 vezes quando se elevou a espessura de revestimento para 1,08 $\pm 0,17 \mathrm{~mm}$ nesta mesma faixa de rugosidade. Sendo este o ensaio que apresentou o maior desgaste.

- Na menor faixa de rugosidade trabalhada, o ensaio envolvendo o CP com espessura de revestimento de $0,45 \pm 0,07 \mathrm{~mm}$ obteve um desgaste $78 \%$ menor em relação ao CP de maior espessura de revestimento $(1,08 \pm 0,17 \mathrm{~mm})$.

- Conforme perfilometria, os pinos de aço não apresentaram desgaste considerável.

\section{AGRADECIMENTOS}

Agradecemos:

- A Universidade Federal de Minas Gerais e aos demais membros do seu corpo docente e discente do programa de Pós-Graduação em Engenharia Mecânica;

- Ao Centro de Microscopia da Universidade Federal de Minas Gerais pelo fornecimento de equipamento e suporte técnico para experimentos envolvendo microscopia eletrônica;

- Ao Instituto Federal de Minas Gerais Campus Ipatinga e aos seus demais servidores.

\section{BIBLIOGRAFIA}

[1] KAMAL, M., EL-BEDIWI, A., LASHIN, A. R. et al., "Copper effects in mechanical properties of rapidly solidified Sn-Pb-Sb Babbitt bearing alloys", Materials Science and Engineering A, v. 530, n. 1, pp. 327332, 2011

[2] ALESHIN, N. P., KOBERNIK, N. V., MIKHEEV, R. S. et al. "Plasma-powder application of antifrictional babbitt coatings modified by carbon nanotubes", Russian Engineering Research, v. 36, n. 1, pp. 46-52, 2016.

[3] VALEEVA, A. K., VALEEV, I. S., FAZLYAKHMETOV, R. F., "Effect of structure of B83 babbit on its wear", Journal of Friction and Wear, v. 35, n. 4, pp. 311-315, 2014.

[4] CARRETEIRO, R. P., BELMIRO, P. N. A., Instituto Brasileiro de Petróleo e Gás: Lubrificantes \& lubrificação industrial, 1 ed., Rio de Janeiro, Interciência, 2006.

[5] ISHIHARA, S., TAMURA, K.., GOSHIMA, T. "Effect of amount of antimony on sliding wear resistance of white metal", Tribology International, v. 43, n. 5-6, pp. 935-938, 2010.

[6] LASHIN, A. R., MOSSA, M., EL-BEDIWI, A. et al., "Study of some physical properties of the rapidly solidified Sn-Sb-Cu-Zn alloys", Materials and Design, v. 43, pp. 322-326, 2013.

[7] VALEEVA, A.K., VALEEV, I.S., FAZLYAKHMETOV, R.F., "Microstructure of the $\beta$-Phase in the Sn11Sb5.5Cu Babbit", Physics of Metals and Metallography, v. 118, n. 1, pp. 48-51, 2017.

[8] ZEREN, A., "Embeddability behaviour of tin-based bearing material in dry sliding", Materials and Design, v. 28, n. 8, pp. 2344-2350, 2007.

[9] LASHIN, A.R., MOSSA, M., KAMAL, M., "Indentation creep and mechanical properties of quaternary Sn - Sb based alloys", Materials Science \& Engineering A, v. 528, n. 10-11, pp. 3568-3572, 2011. 
[10] VALEEVA, A. K., VALEEV, I. S., FAZLYAKHMETOV, R. F. et al., "On the mechanism of runningin during wear tests of a babbitt B83", The Physics of Metals and Metallography, v. 116, n. 5, pp. 509-511, 2015.

[11] EKLUND, S., Roughness effect on friction and wear of lubricated plain bearings, Master's Thesis, Master of Science in Engineering Technology Materials Technology, Lulea University of Technology Department of Engineering Sciences and Mathematics, Sweden, 2013.

[12] HUTCHINGS, I., SHIPWAY, P., Tribology: Friction and wear of engineering materials, 2 ed, London, Butterworth-Heinemann, 2017.

[13] NORTON, R.L., Projeto de máquinas: uma abordagem integrada, 4 ed., Porto Alegre, Bookman, 2013, $1028 \mathrm{p}$.

[14] CHIAVERINI, V., Tecnologia Mecânica: Estrutura e Propriedade das Ligas Metálicas, 2 ed., São Paulo, McGraw-Hill do Brasil, 1986.

[15] GOUDARZI, M.M., JAHROMI, S.A.J., NAZARBOLAND, A., "Investigation of characteristics of tinbased white metals as a bearing material”, Materials and Design, v. 30, n. 6, pp. 2283-2288, 2009.

[16] ÜNLÜ, B.S., "Determination of the tribological and mechanical properties of $\mathrm{SnPbCuSb}$ (white metal) bearings", Materials Science, v. 46, n. 4, pp. 478-485, 2011.

[17] KOROBOV, I. S., NEVEZHIN, S. V., FILIPPOV, M. A. et al., "Effect of Production Methods on Tribological Characteristics of Babbitt Coatings", Journal of Friction and Wear, v. 33, n. 3, pp. 190-194, 2012.

[18] ALMEIDA, J.P.P., Revestimento de Chumaceiras com Ligas à Base de Estanho: Caracterização da interface e estudo da adesão do revestimento ao substrato, Dissertação de Mestrado, Departamento de Engenharia Mecânica do Instituto Superior de Engenharia de Coimbra, Universidade de Coimbra, Portugal, 2014.

[19] JI, X., CHEN, Y., "Tribological Behavior of Babbitt Alloy Rubbing Against $\mathrm{Si}_{3} \mathrm{~N}_{4}$ and Steel Under Dry Friction Condition", Journal of Materials Engineering and Performance, v. 25, n. 3, pp. 750-755, 2016.

[20] SEP, J., TOMCZEWSKI, L., GALDA, L. et al., "The study on abrasive wear of grooved journal bearings", Wear, v. 376-377, pp. 54-62, 2017.

[21] ASSOCIAÇÃO BRASILEIRA DE NORMAS TÉCNICAS, NBR ISO 4287: Especificações geométricas do produto (GPS) - Rugosidade: Método do perfil - Termos, definições e parâmetros da rugosidade, Rio de Janeiro, 2002.

[22] AMERICAN SOCIETY FOR TESTING AND MATERIALS, ASTM E384: Standard Test Method for Knoop and Vickers Hardness of Materials, USA, 2011.

[23] AMERICAN SOCIETY FOR TESTING AND MATERIALS, ASTM G 99 - 05: Standard Test Method for Wear Testing with a Pin-on-Disk Apparatus, United States, 2010.

[24] ASM International - American Society of Metals, Friction, Lubrication and Wear Technology Handbook, USA, 1992.

[25] ZHANG, D., HO, J. K. L., DONG, G. et al., "Tribological properties of Tin-based Babbitt bearing alloy with polyurethane coating under dry and starved lubrication conditions", Tribology International, v. 90, pp. 22-31, Apr. 2015.

[26] ZHANG, D., ZHAO, F., LI, Y. et al., "Study on tribological properties of multi-layer surface texture on Babbitt alloys surface”, Applied Surface Science, v. 390, pp. 540-549, 2016.

[27] AMANOV, A., AHN, B., LEE, M.G., et al., "Friction and Wear Reduction of Eccentric Journal Bearing Made of Sn-Based Babbitt for Ore Cone Crusher”, Materials, v. 9, pp. 950-961, Nov. 2016.

\section{ORCID}

Rafael Martins Ribeiro

Marcelo Araujo Câmara https://orcid.org/0000-0002-9396-4911

https://orcid.org/0000-0003-0617-9163 